\title{
O ENSINO DA CIRURGIA PARA ALUNOS DE GRADUAÇÃo
}

\author{
Guilherme Pinto Bravo Neto, TCBC-RJ
}

A educação continua sendo um dos maiores problemas do Brasil neste fim de milênio. Sem um programa sério de educação, jamais alcançaremos os níveis de Primeiro Mundo. Dados do IBGE revelam que apenas $40 \%$ das crianças brasileiras cursam o ensino médio, o que, apesar de representar um índice melhor do que os observados em passado recente, ainda se mostra muito baixo para uma nação em desenvolvimento. Porém, tão importante quanto a quantidade de alunos nas escolas é a qualidade deste ensino. A impressão do professor universitário é a de que aqueles que ingressam no curso superior estão cada vez mais despreparados, mesmo considerando que a maior parte dos estudantes de universidades públicas seja oriunda de escolas particulares de ensino fundamental e médio, que nos últimos anos vem garantindo um ensino de qualidade superior. Aqueles que, como nós, militam na universidade pública, e, particularmente, na área da saúde, encontram-se no seu dia-a-dia diante da tarefa de oferecer ensino de qualidade a estes jovens em instituições há muito sucateadas.

Mas com idealismo e esforços individuais, grupos esparsos, grandes e pequenos, persistem em querer educar, em querer transmitir conhecimentos e experiências, e resistem àqueles que querem extinguir a universidade pública, esta mesma que vem demonstrando sua superioridade nos provões. E, apesar da importância dos avanços tecnológicos, particularmente no nível da informática e das telecomunicações, das quais se pode lançar mão nas atividades didáticas, ou em modelos pedagógicos, a relação professor/aluno é ainda, a forma mais eficaz de transmissão de conhecimentos. É o fator humano, que estimula o estudo, a pesquisa, a procura pelo aluno de meios avançados ou convencionais de se aprimorar e de sedimentar as informações adquiridas no seu dia-a-dia da Faculdade.

Nossa bem-sucedida experiência como coordenador didático de graduação do Departamento de Cirurgia da Faculdade de Medicina da Universidade Federal do Rio de Janeiro tem demonstrado nestes últimos quatro anos, que esta integração professor/aluno tem sido fundamental no ensino da cirurgia e garantido honrosas observações por parte dos próprios alunos, que classificam nossos cursos entre os melhores da Faculdade de Medicina. Um curso centrado na integração de todos os professores do Departamento de Cirurgia que fazem parte dos diversos serviços cirúrgicos do Hospital Universitário Clementino Fraga Filho, onde o mesmo se desenvolve para alunos do oitavo período do curso médico. Um curso semestral, de 19 semanas, que não aboliu as aulas teóricas, mas desviou seu epicentro para seminários, mesas-redondas e discussão de casos clínicos. As atividades práticas compreendem cerca de $40 \%$ da carga horária e constam de discussão de casos à beira do leito, observação de procedimentos especiais de diagnóstico e, eventualmente, de cirurgias, participação em sessões clínicas, treinamento em manequins em algumas das especialidades, discussão de atos cirúrgicos apresentados em vídeos, ou uma combinação destas atividades, que visam, naturalmente, dar uma informação cirúrgica a pessoas que na sua grande maioria abraçarão especialidades clínicas. O percentual de alunos que seguirão especialidades cirúrgicas tem sido tradicionalmente da ordem de $20 \%$. E talvez, por estas características, a atividade que mais tem estimulado o alunado, é o seminário. Em média, são 18 seminários, um por semana, precedidos de uma avaliação de conhecimentos sobre o assunto e cuja nota entra na média final, em conjunto com as notas das três provas regulares realizadas ao longo do curso. Esta atividade foi considerada pelos alunos a de maior ganho de informação e aprendizado. Nesta mesma linha de atividades situam-se as apresentações de casos clínicos, realizadas pelos próprios alunos e baseadas nos casos estudados durante as aulas práticas. Evidentemente, para realização de todas estas atividades, a turma é dividida em oito grupos de 10 a 12 alunos. E, finalmente, cabe mencionar as mesas-redondas. Foram organizadas 18 mesas redondas sobre assuntos relevantes da área cirúrgica nas diversas especialidades, que ocorrem semanalmente, com a participação de vários professores, que apresentam, moderam e discutem entre si e com os alunos temas cirúrgicos importantes do dia-a-dia de qualquer médico, clínico ou cirurgião.

O curso de cirurgia para alunos de graduação da UFRJ é, portanto, simples e complexo, básico e avançado, mas tem como princípio ativo fundamental a dedicação de seus professores, que vêm ocupando em número cada vez maior o banco de homenageados e paraninfos nas últimas formaturas. Sinais de sucesso são também a procura, a cada ano maior, pelos concursos para monitoria em cirurgia, internato e residência. Muito, ainda há de ser feito. A rápida evolução do conhecimento exige mudanças constantes. Cursos de extensão ajudam a ocupar algumas lacunas, e o CBC tem aí um papel importante, como sede adicional de informações extracurriculares, através de cursos ministrados por seus Membros Titulares, Congressos Regionais e Nacionais.

Enfim, são modelos que dão certo, que precisam ser divulgados e devem servir de incentivo a docentes desestimulados pela atual política econômica e social, que visa denegrir a imagem do ensino superior do setor público. 